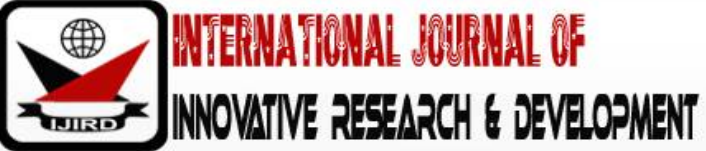

ISSN 2278 - 0211 (Online)

\section{Humanitarian Mitigation Strategies Needed to Buttress the Well-Being of Persons with Disability in Disasters in Kisumu County, Kenya}

Phitalis Were Masakhwe
Assistant Lecturer, Department of Emergency Management Studies,
Masinde Muliro University of Science and Technology, Kenya
Kennedy Onkware
Associate Professor, Department of Emergency Management Studies,
Masinde Muliro University of Science and Technology, Kenya
Susan Kilonzo
Associate Professor, Department of Religion, Theology and Philosophy
Maseno University, Kenya

\begin{abstract}
:
This paper is focused on the fact that some humanitarian mitigation strategies employed are yet to enhance the wellbeing of persons with disabilities in disasters in Kisumu County, Kenya. The problem is that person with disability are not completely involved in crafting of the mention strategies. The study employed semi-structured questionnaire instruments to gather information on humanitarian policies applicable to PWD in disaster context. It was used with humanitarian officers-98 and government officers-98.Further, the researcher adopted semi-structured interviews with open-ended questions which were employed as one of the methods for data collection to provide qualitative data and were complemented by the quantitative data. The researcher used interviews with the regional director of Kenya Red Cross Society, regional directors of UN agencies, the Kisumu County special programs officer, managers of DPOs and director of National Council for People with Disabilities.Secondary data was collected from a variety of sources which included library books, information from journals and other government documents on contributions of humanitarian organizations to the well-being of persons with disability in disaster context. These documents include the national Policy in PWD, Kenya constitution, 2010, UN conventions on PWD. The variables of the study were subjected to descriptive statistics. The qualitative data was analyzed by consolidating emerging themes from the key informant interviews, topic analysis, and cut and paste methods on the focus group discussion transcripts. Quantitative data was analyzed using descriptive statistics such as frequencies and percentages. The researcher presented data findings in form of frequency tables, pie charts, bar graphs and narratives. The study concludes that to reduce the vulnerability of the disabled to disasters, inclusive humanitarian mitigation strategies such as disability focal points in camps or shelters, disability component be part of humanitarian action need to be adopted. The study recommends that humanitarian mitigation strategies include creation of specialized agencies, coordination of humanitarian activities with PWD/DPOs, humanitarian disability programs and individual disaster assistance for PWD. Mitigation strategies on humanitarian relief include decentralizing of humanitarian services by creating deports creation of emergency response systems, rehabilitation and medical services. This would make accessibility of humanitarian relief easier for PWD. Information on PWD can be acquired by way of effective data collection mitigation strategies such as social network tool to capture data on number of persons with disability, online mapping and focused discussion groups in Kisumu County.
\end{abstract}

Keywords: Persons with disability, humanitarian mitigation strategies, humanitarian inclusivity programs

\section{Introduction}

Humanitarian mitigation strategies are supposed to safeguard the well-being of persons with disability in disasters. One critical mitigation strategy to how persons with disability can be mainstreamed into humanitarian programs. On inclusive mitigation strategy, CBM (2018) study argues that the Kenya Red Cross Society (KRCS) has inclusion strategies such as awareness-raising with their response teams during floods in Kisumu County. This is after the organization found that people with disabilities are usually carried to safety on someone's back or transported in a cart for a fee during floods. This study is relevant since it highlights the need to build capacity with humanitarian actors. This makes disability an aspect of humanitarian planning where by the humanitarian staff are able to identify disabled people 
easily during disasters and therefore, are able to evacuate them. But the study does not indicate the participation of persons with disability in the pre-humanitarian planning. Also, Surpriya et al (2018) argue that, KRCS had put in place early warnings of the floods and mapping was done by the support of local authorities and leaders. They go further to say that this enabled the response teams to identify households that were most at risk. The problem is that these inclusive strategies on early warning and awareness are one sided. For purposes of inclusion, there are specific approaches that need to be employed. Kett et al, (2017), for example, argues that in Kisumu two focus group discussions were held with people with disabilities (one with men and the other with women) so that they are part of humanitarian action. However, some of the strategies are knee-jerk since they take place in the aftermath of disasters. Therefore, there was need to explore mechanisms that are consistent and address the loopholes in the entire humanitarian cycle with regard to wellbeing of person with disability in Kisumu County.

\section{Materials and Methods}

The land area of Kisumu County totals $2085.9 \mathrm{~km}^{2}$. Kisumu County neighbours Siaya County to the West, Vihiga County to the North, Nandi County to the North East and Kericho County to the East. Its neighbour to the South is Nyamira County and Homa Bay County is to the South West. The county has a shoreline on Lake Victoria, occupying northern, western and a part of the southern shores of the Winam Gulf. The county has an annual relief rainfall that ranges between $1200 \mathrm{~mm}$ and $1300 \mathrm{~mm}$ in different sectors. The rain mainly falls in two seasons. Kisumu is known for its thunderstorms, which are the major type of precipitation and normally occur in mid-afternoon during the rainy season. Kisumu is warm throughout the year with a mean annual temperature of 23. 0C. The temperature ranges between $200 \mathrm{C}$ and $350 \mathrm{C}$ but seldom falls below 19 0C. The climate of Kisumu County makes it vulnerable to floods in some areas such as Nyando. The population of persons with disability and their households in Kisumu county is about15, 760 (National Council for People with disability, 2019). A section of this population was affected by post-election violence in 2007/ 8 (Abonyo, 2015). He argues that in this uncertainty some disabled persons were left behind as they struggled for safety, food, protection and recognition from the community. It was of much threat to life as more cases of physical disabilities were reported with others getting injured in the conflict. Nyakundi (2010) concurs that during the post-election violence more that $20 \%$ of disabled persons were faced with the challenge of accessing food from shopping centers due to protracted Post-Election violence. Also, Kisumu County is affected by both natural and man-made disasters such as floods, political unrests among others. The study employed semi-structured questionnaire instruments to gather information on humanitarian policies applicable to PWD in disaster context. It was used with humanitarian officers-98 and government officers-98.The researcher adopted semi-structured interviews with open-ended questions which were employed as one of the methods for data collection to provide qualitative data and were complemented by the quantitative data. The researcher used interviews with the regional director of Kenya Red Cross Society (1), regional directors of UN agencies (2), the Kisumu County special programs officer-1, managers of DPOs (3) and director of National Council for People with Disabilities1.The researcher collected secondary data from a variety of sources. This included library books, information from journals and other government documents on issues of humanitarian policy and well-being of persons with disability in disaster context. These documents include the national Policy in PWD, Kenya constitution, 2010, UN conventions on PWD. The research instruments were trial tested in Kakamega County. Feedback from the pilot study was used to revise the instruments for final data collection. The respondents in the pilot phase were excluded during the final administration of the instruments. The questionnaires used were open and closed questions intended to capture a detailed level of content. It is chosen due to its ability to reach distant respondents hence minimized researchers influence on the respondents. It also allowed time for respondents to give well thought answers and time to respond to the items.The researcher cleaned data by listing, remove errors and check extreme values and edit to ensure conformity. The group survey data were analyzed using SPSS Version 12. The variables were subjected to descriptive statistics. The qualitative data was analyzed by consolidating emerging themes from the key informant interviews, topic analysis, and cut and paste methods on the focus group discussion transcripts. Quantitative data was analyzed using descriptive statistics such as frequencies and percentages. The researcher presented data findings in form of frequency tables, pie charts, bar graphs and narratives.Persons with disability face stigmatization in society and therefore, finding them could be difficult. This was a great challenge to the researcher to collect data. The research addressed this issue by employing snowballing. Further, the sub-county commissioners with relevant information assisted. Secondly, some respondents declined to participate due to the sensitivity of the topic. The researcher used secondary data from publication on issues of humanitarianism with regard to PWD in disaster contexts to beef up his data and information. Thirdly, language was of great challenge in remote areas or some respondents had hearing impairment since some of the respondents were unable to communicate in either English or Kiswahili. On this, the researcher engaged research assistants who speak local language and sign language interpreter for the deaf.

\section{Findings and Discussions}

Humanitarian mitigation strategies adopted need to be effective in securing the well-being of persons with disability in disaster situations. To gather data on this, the researcher asked humanitarian and government officers to identify humanitarian mitigation strategies that can reduce the vulnerability of person of disability to disasters. The total number of respondents was 196. Three questionnaires were not returned. The following table is a summary of findings on humanitarian mitigation strategies that can reduce the vulnerability of person of disability to disasters. 


\begin{tabular}{|c|c|c|}
\hline Vulnerability Mitigation Strategies & Frequency & Percentage (\%) \\
\hline Create specialized agencies & 99 & 51.3 \\
$\begin{array}{c}\text { Tailor individual disaster assistance } \\
\text { for PWD }\end{array}$ & 94 & 48.7 \\
\hline $\begin{array}{c}\text { Coordinate humanitarian activities } \\
\text { with PWD/ DPOs }\end{array}$ & 97 & 50.3 \\
\hline Humanitarian Disability programs & 96 & 49.7 \\
\hline
\end{tabular}

Table 1: Vulnerability Mitigation Strategies for PWD

Table above table indicates that 99(51.3\%) agreed to creation of specialized agencies while 97(50.3\%) to coordinated humanitarian activities with PWD/ DPOs. 96 (49.7\%) and 94(48.7\%) agreed to humanitarian disability programs and individual disaster assistance for PWD respectively. Data indicates that creation of specialized agencies is important since that would specifically focus on the special needs of PWD. The result indicates that the most preferred mitigation strategy is creation of specialized agencies, humanitarian disability programs and individual disaster assistance. In an FDGinterview, a DPO Member argued:

Special agencies will handle PWDs unique needs well. Such agencies will handle issues to with medication (Interview held on 23rd May, 2019 in Nyando).

The statement indicates the wish of persons with disability for specialized agencies to handle health issues. Data indicate that 96 (49.7\%) of the sampled agreed to specific disability programs. In an interview, a head of a household was of the view that specific humanitarian programmes on socio-economic issues that crop up because of disasters are needed. Abonyo (2015) study found out that the aftermath of Post-Election Violence in Kisumu, PWD had to depend on community support, personal strategies, support from government and non-governmental organization to survive. This means that there were no concrete no humanitarian strategies on how to socio- economically support PWD after disasters destroy their livelihoods.

On supply of relief items, the researcher asked humanitarian and government officers to highlight how the wellbeing of the disabled can be secured by humanitarian relief mitigation strategies. The total number of respondents was 196. Three questionnaires were not returned. The following figure is a summary of findings on mitigation strategies on humanitarian relief:

\section{Humanitarian Relief Mitigation Strategies}

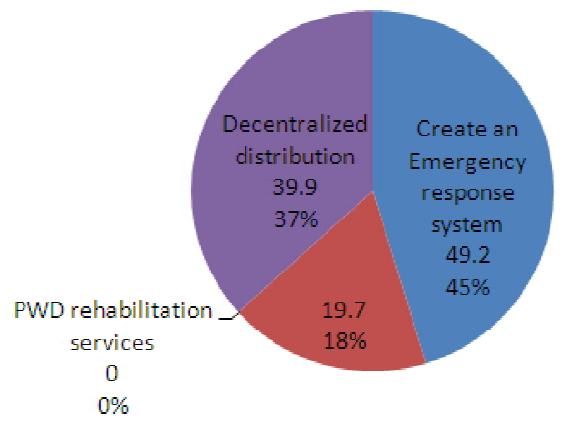

Figure1: Humanitarian Relief Strategies

Source: Field Data, 2019

Figure above indicates that (45\%) of the respondents agreed to creation of emergency response systems while (37\%) to decentralize distribution of relief items. (18\%) agreed to rehabilitation and medical services specifically for PWD. The result indicates that a majority of the respondents prefer creation of emergency response systems as first priority followed by decentralization of distribution points for ease access. On emergency response systems, (45\%) of the sampled agreed that persons with disabilities are overlooked and marginalized during the emergency or relief phase in disaster prone areas of Kisumu County.

A DPO official argued that persons with disabilities need to be part of emergency planning, assessment, design, and delivery of humanitarian relief strategies in disasters. A head of household concurred that humanitarian agencies collaboration in building of emergency response system would decentralize medical facilities across Kisumu County. It is also important to provide counseling, training programs, and other kinds of services that will assist them with difficult social and economic transitions. In an FDG Interview, a member opined:

Comprehensive guidelines on emergency shelters, humanitarian facilities, and other post-disaster infrastructures are some of the strategies that can be employed (FDG interview held on 21st May, 2019 in Kisumu City) 
This assertion indicates that emergency shelters need to be designed in a way that PWD can access easily. Surpriya et al., (2018) observed that in 2015, KRCS was on the forefront in evacuating PWD in Nyando flooded area using a canoe. They argue that KRC had emergency respond programs to provide for persons with disability. However, the input of persons with disability should inform humanitarian program design on emergency respond systems with regard to disasters that afflict them in Kisumu County.

Secondly, data indicates that 38(18\%) of the sampled agreed to rehabilitation and medical services specifically for PWD in disasters. To guarantee health of PWD, medical and rehabilitation services need to be set-up in a way that persons with disabilities living in remote areas can access these services. In an interview, a household head argued that there is need to develop facilities and mobile teams to ensure persons with disabilities with difficulties in moving have access to essential health services. To ensure a timely and decentralized response during disasters, these mobile units should be established at both the county and sub-county-levels. To make them effective and improve coordination, local Kisumu County DPOs should be included in emergency medicine trainings and response planning efforts.

On rehabilitation of PWD in post-disasters periods, a special programmes officer argued that the county government of Kisumu needs to build greater capacity in rehabilitation and ensure that these facilities are decentralized and accessible to persons with disability before, during, and after a disaster. There should be a system of equipment depots to ensure that assistive devices and assistive technology locally available in disaster context.

On food and non-food relief items, 77(38\%) of the sampled agreed that these items need to be decentralized. To decentralize distribution points across the county, humanitarian organizations are to plan in consultation with local DPOs for selection of type of items. It was observed that access to relief items can be a challenge due to ragged terrain and limited physical infrastructure in Kisumu County. This makes it necessary for these services and depots to be spatially distributed in a decentralized manner for accessibility to rural as well as urban populations. Similarly, it is critical to coordinate these programs with local DPOs and Government officials at the County level.

On accessibility of relief supplies, the researcher asked humanitarian and government officers to identify how disabled person's well-being can be guaranteed through humanitarian strategies on humanitarian assistance. The total number of respondents was 196. Three questionnaires were not returned. The following table is a summary of findings on humanitarian strategies on accessibility of humanitarian assistance to PWD:

\begin{tabular}{|c|c|c|}
\hline Accessibility Strategies for PWD & Frequency & Percentage (\%) \\
\hline Inclusive access to information & 95 & 49.2 \\
\hline $\begin{array}{c}\text { Access to humanitarian relief(Facilitation } \\
\text { of transportation) }\end{array}$ & 77 & 39.9 \\
\hline
\end{tabular}

Table 2: Humanitarian Strategies on Accessibility to Humanitarian Assistance for PWD

Source: Field Data, 2019

Table above indicates that 95(49.2\%) of the respondents agreed that access to information on impeding disasters while $77(39.9 \%)$ to access to humanitarian relief by facilitation on evacuation and access relief distribution points. Washington Disability Group (2018) observes that humanitarian organization like KRCS have humanitarian relief strategies on PWD in Kisumu County. However, Abonyo (2015) argued that that during the 2007/ 2008 post-election violence PWD were caught off guard because of lack of information and struggled to access relief services.

In an interview, a humanitarian officer argued that humanitarian agencies need to build communication capacity prior to a disaster. These include pre-writing public service announcements in multiple languages on questions that frequently arise during disasters would suffice.A humanitarian officer argued that it could include: auditory signals or alarms (sirens, bells, drums) visual signal systems (flags, posters written with large characters or pictures that are colour contrasted); turning light off-on frequently; clear and brief announcements; door to door notification and assistance for identified vulnerable people. CBM (2018) study found that KRCS had put in place early warnings of the floods and mapping was done by the support of local authorities and leaders. This enabled the response teams to identify households that were most at risk. The weakness in this strategy is that persons with disability were not involved in the whole process.A humanitarian officer argued that these disability early warning systems need to be developed in preparedness phase, with support of persons with disabilities or DPOs working with them and be field tested. There should be early warning task forces as well as the community need to be trained using early warning systems which include mock drills. Persons with disability must participate in training, for example, if a visually impaired person knows that holding tight and pressing firmly the forearm 5 times means 'floods are rising, we need to go to the shelter immediately", this would save lives through a simple measure. Humanitarian actors need to close information gap between them and PWD. This would make accessibility to relief services easier for them.

On humanitarian response which involves the search, rescue and evacuation, persons with disabilities need to assisted since some family members or care takers are lost or injured as a result of crisis. Supriya et al (2018) argued that KRCS evacuated persons with disability using a canoe since they knew how to locate them. However, a DPO official argued that the search and rescue teams need to be well equipped to deal with persons with disabilities.

On shelter management, a DPO official argued that the design needs to be standard so that access of persons with disabilities to services such as water and sanitation, food distribution is made easier. This would ensure that no extra human resources are required to provide them with assistance to use the shelter's facilities. Thus, accessibility to humanitarian relief by the disabled depends on design of shelters. This also includes design of features such as latrines, bathrooms, water points, wells etc. In an FDG interview, a member argued: 
People with disabilities or representatives need to participate in shelter design. This includes people with disabilities in shelter management committees and raise awareness about disability in the community and among disaster management teams (FDG interview held on 23 $3^{\text {rd }}$ may 2019 in Manyatta).

This assertion means that participation of PWD in shelter management is critical to how they are designed as per their special needs. A special program officer argued that humanitarian shelter management can promote peer support mechanisms. In an FDGinterview, a DPO Member argued:

Disabled persons have capacities to deal with life in shelters and camps Support from volunteers, shelter task forces and peer support is needed (interview held on 24th May, 2019 in Nyando)

This assertion indicates that support from volunteers in camps is a strategy on assisting PWD in shelters or. A humanitarian officer indicated that the shelters include toilets or latrines. On the other hand, distribute assistive and mobility devices would increase persons with disabilities' capacities and autonomy in shelters.

On the other hand, distribute assistive and mobility devices would increase persons with disabilities' capacities and autonomy in shelters. In an FDG interview, a DPO member argued:

Disability Focal Points(DFP) in the camps or shelters would enable persons with disabilities, family members and care takers to get information about services available linked to shelter management, food and crop distribution, general evolvement of the disaster situation, employment opportunities, specialist services such as physical rehabilitation (interview held on 25th May, 2019 in Manyatta)

This assertion indicates the importance of having Disability Focal Points (DFPs) in camps. Disability Focal Points provide information, offer specialist services according to human and material resources available such as home to home services, assistive and mobility devices and psycho-social support. A humanitarian officer, however, argued that humanitarian response team needs to have special educators that teach sign language for communication and literacy for people with hearing impairment. Moreover, braille for communication and literacy for people with severe visual impairment is a strategy on access of information. On mobility training, they support people with severe visual impairment to move an independently as possible around their local area. In an FDG interview, a DPO member lamented: Humanitarian actors need to facilitate us with transportation support so as to reach relief distribution centres without difficulty (FDG interview held on 23rd May 2019 in Manyatta area.

This assertion indicates that provision of affordable or free transport or outreach services is important. There is need to assess the location of PWD so as to estimate transport fee or cost. CBM (2015) study observed that PWD were carried by able-bodied persons to access humanitarian relief because they are limited in mobility. Therefore, creation of disability focal points and universal design of facilities is critical. This approach would increase the efficiency and appropriateness of the immediate disaster response and to increase awareness about social exclusion and disability before a disaster occurs. For these strategies to be effective, humanitarian organizations need accurate data on PWD without which their efforts are null and void.

On data collection strategies, the researcher asked humanitarian and government officers to identify effective data collection strategies on PWD so that they can easily reach them. The total number of respondents was 196 . Three questionnaires were not returned. The following figure is a summary of findings on data collection methods on PWD so that they effectively access humanitarian assistance in disasters:

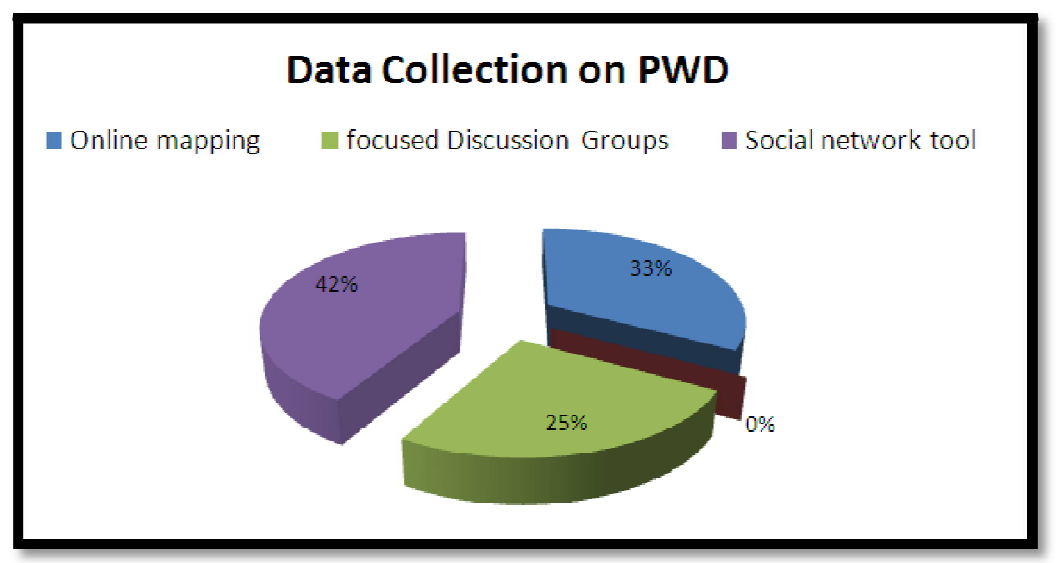

Figure 2: Data Collection Strategies on PWD Source: Field Data, 2019

Figure above indicates that (42\%) agreed to using social network tool to capture data on number of persons with disability while (33\%) and (25\%) agreed to online mapping and focused discussion groups respectively. Data indicates that (33\%) of those sampled indicated that online mapping is an important strategy in identifying disabled persons easily in times of disasters. A humanitarian officer argued that this method is important in the search and rescue processes during disasters. For evacuation to be effective, disabled persons need to be included in emergency mock drills, so they know what an evacuation is, what are Search Rescue and Emergency (SRE) teams, where the safe haven or the shelter is. The mapping should also include family members and care takers of persons with disability.

Data indicate that (42\%) of those sampled agreed that social networking to capture data on number of persons with disability is utilized. This method is important since PWD are known to people in the locality and therefore use of 
focus group discussions, individual household surveys for comprehensive information and crosschecking of it could be important. Social network tool includes structured interviewing at home through Community Based Rehabilitation (CBR) workers. The importance of this method is in allowing private conversation with PWD to explain their ideas and needs. Data indicates that (25\%) of those sampled identified focus discussion groups as a representative way that include people with different types of impairment (or their representatives) to ensure information is provided related to different types of impairments. A head of a household argued that FGDs are very important method for participation of PWD if the accessibility and distance for PWD are considered. Surpriya et al (2018) argued identifying people with disabilities through disability cards given by the Kenya government does under-report of the number of people with disabilities. As a result, the Kenya Red Cross Society plans to use the Washington Group questions to identify people with disabilities in near future. In an interview, a household officer argued:

There is need for routine administrative data through CBR programme - Through the CBR workers, the PWD are identified, registered and assess their condition for further interventions (Interview held on 23 ${ }^{\text {rd }}$ 2019, in Kisumu City).

This statement calls for routine identification of PWD so that new cases are recorded. Humanitarian actors can only achieve this through community based rehabilitation programs. The participation of persons with disabilities in data collection is too critical to be ignored by humanitarian actors. Therefore, data collection mitigation strategies determine how effective humanitarian actors can easily monitor and locate them during disasters. For evacuation to be effective, disabled persons need to be included in emergency mock drills, so they know what an evacuation is, what are Search Rescue and Emergency (SRE) teams, where the safe haven or the shelter is.

On inclusion of DPOs into humanitarian action, the researcher asked humanitarian and government officers what mitigation strategies can be adopted to incorporate DPOs into humanitarian action. The total number of respondents was 196. Three questionnaires were not returned. The following figure is a summary of findings how DPOs can be incorporated DPOs into humanitarian action:

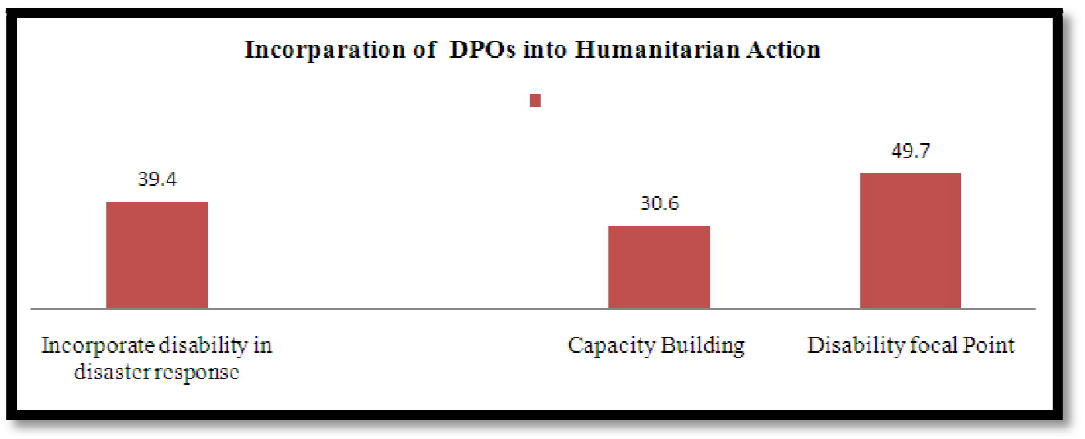

Figure 3: Humanitarian Mitigation Strategies for DPOs Source: Field Data, 2019

Figure above indicates that (49.7\%) of the respondents agreed to creation of disability focal points in areas where DPOs are located while (39.4\%) agreed to incorporation of disability into DPOs programs. Lastly, (30.6\%) agreed to capacity building in DPOs in Kisumu County. Mitigation strategies identified were to mainstream DPOs into humanitarian programs.

Data indicates that 96(49.7\%) of those sampled agreed that creation of disability focal points in areas where DPOs are located would boost flow of information between humanitarian actors and the disabled. This would automatically mainstream disability within clusters and operational agencies, and support coordination between humanitarian organisations such as UN agencies, DPOs and local authorities. Data indicates that (30.6\%) agreed to capacity building in DPO. A DPO officer was of the view that the need to provide capacity building to DPOs staff on humanitarian planning which includes coordination mechanisms and response interventions is important. Such would support their capacities in developing response activities critical to humanitarian action. In an FDG interview, a DPO member argued:

To have capacity building among persons with disability DPOs are strategic since they have structures to the grass roots (interview held on 23rd May, 2019 in Nyando)

This statement indicates that engaging DPOs as a strategy to reach PWD would be effective in many ways. Therefore, capacity building in DPOs is a sure way of promoting awareness among PWD. Local DPO structures can be utilized to build capacity among PWD.Thus, the need for mitigation strategies for DPOs includes capacity building, disability focal points in areas where DPOs are located and incorporate disability in DPOs. Capacity building among PWD can be realized through DPOs. There is need to build capacity in disability representative organizations such as DPOs so that humanitarian action is localized as opposed to it being urbanized

\section{Conclusion}

The findings indicate that humanitarian strategies adopted to safeguard the well-being of PWD are ineffective and thus need to adapt more robust ones. These mitigation strategies on humanitarian relief include decentralizing of humanitarian services by creating deports creation of emergency response systems, rehabilitation and medical services. This would make accessibility of humanitarian relief easier for PWD.Information on PWD can be acquired by way of effective data collection mitigation strategies such as social network tool to capture data on number of persons with disability, online mapping and focused discussion groups.Data collection mitigation strategies determine how effective 
humanitarian actors can easily monitor and locate them during disasters. Mitigation strategies for DPOs include capacity building, disability focal points in areas where DPOs are located and incorporate disability in DPOs. Capacity building among PWD can be realized through DPOs. There is need to build capacity in disability representative organizations such as DPOs so that humanitarian action is localized as opposed to it being urbanized. From the key findings of this paper, the study concludes that to reduce the vulnerability of the disabled to disasters, inclusive humanitarian mitigation strategies such as disability focal points in camps or shelters, disability component be part of humanitarian action need to be adopted.

\section{References}

i. Abonyo, M., (2015). Armed Conflict and Coping Mechanisms of Disabled Persons: A Case Study of Conflict in Kisumu, 2007 - 2013, University of Nairobi. Nairobi: Human Rights Watch

ii. CBM International, (2018).Humanitarian inclusion standards for older people and people with disabilities. Geneva: Published by the Age and Disability Consortium

iii. Kett, M., Smith, F., Simard, M., Twigg, J.\& Cole, E. (2017). Disability and Climate Resilience: A literature review. Leonard Cheshire Research Centre: London. URL: https:/ / www.ucl.ac.uk/ iehc/ research/ epidemiology-publichealth/ research/ leonard-

cheshireresearch/research/publications/documents/2017/ Disability_and_Climate_Resilience_Lit_review.pdf

iv. Nyakundi, H., S, Mogere. \& Yitambe, A. (2010). Community perceptions and response to flood risks in Nyando District, Western Kenya. Journal of Disaster Risk Studies 3(1): 346-366.

v. Supriya, A. \& Rhea, B. (2018). Good practice guide: Embedding inclusion of older people and people with disabilities in humanitarian policy and practice. Oxford: Oxford Brookes University Publication 